\title{
Assessment of the effect of estradiol on biochemical bone turnover markers among postmenopausal women
}

\author{
Konrad Jamka ${ }^{1, A-F}{ }^{\oplus}$, Piotr Adamczuk ${ }^{1, B-C} \oplus$, Agata Skowrońska ${ }^{1, B}{ }^{\oplus}$, Iwona Bojar ${ }^{2, B-C, E} \oplus$, \\ Grzegorz Raszewski,A,C-F(i) \\ 1 Department of Toxicology and Food Safety, Institute of Rural Health, Lublin, Poland \\ 2 Department for Women's Health, Institute of Rural Health, Lublin, Poland \\ A - Research concept and design, B - Collection and/or assembly of data, C - Data analysis and interpretation, \\ $D$ - Writing the article, E - Critical revision of the article, $F$ - Final approval of article
}

Jamka K, Adamczuk P, Skowrońska A, Bojar I, Raszewski G. Assessment of the effect of estradiol on biochemical bone turnover markers among postmenopausal women. Ann Agric Environ Med. 2021; 28(2): 326-330. doi: 10.26444/aaem/135529

\begin{abstract}
Introduction. Estrogen deficiency found in postmenopausal women may lead to disturbances in the balance of bone metabolism. Study of the influence of estradiol on markers of bone turnover may help to understand the mechanisms of bone metabolism and to monitor osteoporosis therapy in postmenopausal women at high risk of fractures. The aim of the study was evaluation of the effect of estradiol on the basic markers of bone turnover in postmenopausal women.

Materials and method. The study was conducted in a group of 92 postmenopausal women, divided into two groups: Gr-1 with low estradiol levels $\leq 10 \mathrm{pg} / \mathrm{ml}$ and $\mathrm{Gr}-2$ with reference estradiol levels $\geq 25 \mathrm{pg} / \mathrm{ml}$ ). Basic markers of bone turnover were examined: Ctx (C-terminal cross-linked telopeptide of type I collagen alpha chain) and OC (osteocalcin); pro-resorptive cytokines: IL-6 and TNF-a; vitamin 25(OH)D3 and lipid profile. Women was also analyzed according to demographic and clinical data.

Results. A positive relationship was found between estradiol and the main bone formation marker $-O C(p=0.041, r=0.213)$ and IL-6, TNF- $a(p=0.007, r=0.281$ and $p=0.018, r=0.246$, respectivly, but only in the group with a reference hormone level. Moreover, the main markers of bone turnover: $C t x$ and OC showed a mutual positive correlation $(p=0.013 ; r=0.257)$ in women with reference estradiol levels. Relationships between markers of bone remodeling, pro-resorptive cytokines and vitamin D3 depending on the level of estradiol showed no statistically significant correlation.

Conclusions. The study showed that only in women with the reference estradiol level ( $\geq 25 \mathrm{pg} / \mathrm{ml}$ ) were the bone formation and resorption processes balanced.
\end{abstract}

Keywords

estradiol, bone turnover markers, postmenopausal, osteoporosis

\section{INTRODUCTION}

Osteoporosis is defined as a systemic skeletal disorder characterized by low bone mass and disorganization of the internal microarchitecture of bone tissue [1]. The most severe clinical symptom of osteoporosis are bone fractures, and due to the treatment-related costs osteoporosis has become an important medical, social, and economic problem [2].

In mature skeleton the dominant process is bone remodelling. Processes of bone formation and resorption are mutually closely related, and in a healthy individual they remain in a relatively balanced state [3]. The amount of bone tissue that is resorbed is equal to the amount which is subsequently formed in each unit of bone remodelling. This process enables continuous bone renewal, while maintaining a relatively constant mass and resistance [3].

After menopause, the normal cycle of bone turnover is disturbed by estrogen deficiency caused by the loss of hormonal function of the ovaries observed in women at that time. Osteoclastic resorption activity increases while osteoblastic activity decreases. As a result, the amount of

Address for correspondence: Grzegorz Raszewski, Department of Toxicology and Food Safety, Institute of Rural Health, Jaczewskiego 2, 20-090 Lublin, Poland E-mail: raszewski.g@imw.lublin.pl

Received: 14.01.2021; accepted: 06.04.2021; first published: 13.04.2021 the resorbed bone exceeds the amount of bone embedded in the remodelling units, which leads to net bone loss. An increase in overall bone resorption is caused by inhibited bone resorption due to decreased availability of estrogen in both osteoclastogenesis and osteoclast activity [4].

Healthy bone requires constant remodelling which is the key process for maintaining its proper density. It is estimated that nearly $10 \%$ of bone mass is remodelled annually [4]. Metabolism of bone tissues and the process of bone remodelling are regulated by many factors, to which belong mainly hormones, as well as local growth factors and physical factors. Osteoclasts (bone breakers) and osteoblasts (bone builders) play a crucial role in the process of bone remodelling. These are two types of cells which basically form a multicellular unit of bone, coordinating the balance between bone formation and bone resorption. Cell differentiation towards osteoblasts and osteoclast is strictly controlled by both local and systemic factors [5], a regulated by several hormones, including parathyroid hormone, calcitonin, vitamin $\mathrm{D}_{3}$, and estrogen [4].

Estrogens play a key role in the maintenance of bone mass and stabilization of bone metabolism [6]. Estrogens exert a direct effect on the maintenance of bone mineral density through a variety of mechanisms in osteoclasts, osteoblasts and osteocytes, and other cells by binding to 
estrogen receptor alpha $(\mathrm{ER} \alpha)$ and beta $(\mathrm{ER} \beta)$. However, the roles of estrogen's receptors in the bone matabolism are beginning to be elucidated and the facts show than $\mathrm{ER} \alpha$ and $\mathrm{ER} \beta$ antagonize each other in bones and other tissues [7]. Estrogens may also act indirectly by inhibition of the resorptive activity of osteoclasts and stimulation of osteogenesis by osteoblasts. Osteoblasts inhibit the secretion of resorptive cytokines IL-1, IL- 6 and TNF- $\alpha$, which act as paracrine regulators of osteoblasts [8].

Measurements of the levels of biochemical markers of tissue metabolism (BTM) excellently present all processes of bone formation and bone resorption simultaneously taking place in the whole skeleton (BTM). Therefore, their determination in blood serum/plasma or urine enables an early diagnosis of change in the level of bone tissue metabolism. However, it should be considered that the level of BTM constantly changes according to the hormonal status, age, season of the year, or time of day $[9,10]$.

The main biochemical markers of bone formation include: bone fraction of alkaline phosphatase (BAP), osteocalcin (OC), procollagen type 1 amino-terminal propeptide (P1NP), procollagen type 1 carboxy-terminal propeptide $(\mathrm{P} 1 \mathrm{CP})$, receptor activator of nuclear factor-kappa B ligand (RANKL), and osteoprotegerin (OPG). The biochemical markers of bone resorption are: hydroxyproline (HYP), pyridinoline (PYD) deoxypyridinoline (DPD), N-terminal cross-linked telopeptide of the type I collagen alpha chain (Ntx), C-terminal cross-linked telopeptide of the type I collagen alpha chain (Ctx), carboxy-terminal cross-linked telopeptide of type I collagen (ICTP), type I collagen alpha 1 helicoidal peptide (HELP), tartrate resistant acid phosphatase isoform 5b (TRAP5b), cathepsin $\mathrm{K}$, sclerostin ( $\mathrm{Scl}$ ), and DKK1 protein [9].

In the presented study, two markers were used for evaluation of bone tissue metabolism, characterized by high diagnostic efficiency: c-terminal telopeptide of type 1 collagen (Ctx) as a marker of bone resorption, and osteocalcin (OC) as a marker of bone formation [9].

Simultaneous application in tests of the markers of both synthesis and resorption of the bone cells allows visualization of the pace and intensity of opposing processes of bone formation and resorption, with the participation of bone tissue osteoblasts and osteoclasts $[10,11]$. In addition, the investigation of bone hormonal and biochemical markers is useful while assessing bone turnover in postmenopausal women, facilitates clinicians' identification of patients at high risk of fractures, and allows an effective monitoring of anti-resorptive therapies [12].

\section{OBJECTIVE}

The aim of the study was evaluation of the effect of estradiol on the basic markers of bone turnover in postmenopausal women.

\section{MATERIALS AND METHOD}

Patients and study design. The study was conducted in a selected group of 92 postmenopausal women, based on faceface interview and a survey. The criteria for inclusion into the study were age between 50-65 and absence of menstrual periods for at least two years, whereas the criteria of exclusion were active cancerous diseases within five years prior to recruitment, an active inflammatory condition and alcohol abuse. Based on the determined estradiol level, this group was subsequently divided into two study groups: Group 1 - women with a decreased serum estradiol level $\leq 10 \mathrm{pg} /$ $\mathrm{ml}$ (Gr-1), n=52, and Group 2 - women with normal serum estradiol level $\geq 25 \mathrm{pg} / \mathrm{ml}$ (Gr-2), $\mathrm{n}=40$ (referential values).

Basic markers of bone tissue metabolism were examined: C-terminal cross-linked telopeptide of the type I collagen alpha chain (Ctx) - as a marker of bone resorption, and osteocalcin (OC) - as a marker of bone formation; vitamin $25(\mathrm{OH}) \mathrm{D}_{3}$; pro-resorptive cytokines: interleukin 6 (IL-6) and tumour necrosis factor-alpha (TNF- $\alpha$ ), and lipid levels (total cholesterol, triglycerides, HDL-cholesterol and LDLcholesterol). The examined group of women was also analyzed according to age, BMI, education level (incomplete primary, primary, vocational, secondary school, university); place of residence (city, town, rural); type of occupation performed (manual, non-manual, both manual and non-manual).

Serum levels of: OC, Ctx, vitamin $25(\mathrm{OH}) \mathrm{D}_{3}$, cytokines IL- 6 and TNF- $\alpha$ were determined using the following tests: Osteocalcin ELISA assay; Serum CrossLaps One Step ELISA assay (Bioscience A/S, Denmark); 25(OH)D EIA assay Kit (R\&D Systems, USA); Quantikine HS IL- 6 and TNF- $\alpha$ ELISA Kit (R\&D Systems, USA).

Lipoid levels were determined by means of an automated chemistry analyzer (Express Plus Analyzer, Chiron, USA), and Siemens reagents (Siemens Healthcare Diagnostics, USA). All determinations were performed in accordance with procedures provided by the producers of the reagents and tests.

Statistical analysis. Statistical and graphic analyses were performed using the software GraphPad Prism 5. The results were presented as the mean value $(\mathrm{x}) \pm$ standard deviation (SD), or as \% of a given population. Statistical differences were investigated using: for variables with normal distribution - t-Student test, and for variables with non-parametric distribution - Mann-Whitney U test.

In regression analysis, Pearson's correlation coefficient was calculated. In all statistical analyses the $\mathrm{p}$ values $\mathrm{p} \leq 0.05$ were considered statistically significant.

\section{RESULTS}

Table 1 presents the collected demographic and clinical data concerning the examined women.

The mean age of women participating in the study was $56.54 \pm 3.76$ years, BMI $-26.2 \pm 4.4$, they had mainly higher education (44.6\%) and secondary school education (42.4\%), and lived in large cities (58.7\%). The mean level of estradiol was $20.9 \pm 21.0 \mathrm{pg} / \mathrm{ml} ; 5.6 \pm 2.3 \mathrm{pg} / \mathrm{ml} \mathrm{w} \mathrm{Gr}-1$, and $40.8 \pm$ $17.3 \mathrm{pg} / \mathrm{ml}$ in Group 2 (Tab. 1).

The determined levels of vitamin $\mathrm{D}_{3}$; Ctx; OC; cytokines IL- 6 and TNF- $\alpha$, and lipids: total-cholesterol; HDLcholesterol; LDL-cholesterol and triglycerides was: $21.9 \pm$ $13.0 ; 0.54 \pm 0.16 \mu \mathrm{g} / \mathrm{L} ; 10.7 \pm 3.7 \mu \mathrm{g} / \mathrm{L} ; 2.05 \pm 1.87 \mathrm{pg} / \mathrm{ml} ; 3.13$ $\pm 1.69 \mathrm{pg} / \mathrm{ml}$, and $224.7 \pm 44.8 ; 53.7 \pm 13.0 ; 141.4 \pm 44.7$ and $148.2 \pm 61.4$, respectively (Tab.1).

No statistically significant differences in demographic data, level of vitamin $25(\mathrm{OH}) \mathrm{D}_{3}$, pro-resorptive cytokines: 
Table 1. Respondents' characteristics

\begin{tabular}{|c|c|c|c|}
\hline Postmenopausal women & $\begin{array}{l}\text { Total } \\
\mathrm{n}=92\end{array}$ & $\begin{array}{c}\text { Group-1 } \\
n=52\end{array}$ & $\begin{array}{c}\text { Group-2 } \\
n=40\end{array}$ \\
\hline Age, years, mean $\pm(S D)$ & $56.54(3.76)$ & $56.81(3.80)$ & $56.20(3.73)$ \\
\hline Education;\%; primary & 4.3 & 2.0 & 7.5 \\
\hline vocational & 8.7 & 9.6 & 7.5 \\
\hline secondary school & 42.4 & 42.3 & 42.5 \\
\hline university & 44.6 & 46.1 & 42.5 \\
\hline $\mathrm{BMI}, \mathrm{kg} / \mathrm{m}^{2} ;$ mean $\pm(\mathrm{SD}) ; \%$ & $26.2(4.4)$ & & \\
\hline$<18.5$ (underweight) & $16.9(4.1) ; 2.2$ & $16.9(1.5) ; 3.8$ & 0.0 \\
\hline $18.5-25$ (normal weight) & $22.5(4.5) ; 40.2$ & $22.4(1.4) ; 32.7$ & $22.4(1.3) ; 50.0$ \\
\hline $25-30$ (overweight) & $27.4(1.3) ; 37.0$ & $27.2(1.3) ; 44.2$ & $27.9(1.2) ; 27.5$ \\
\hline$>30$ (obesity) & $32.6(2.9) ; 20.6$ & $33.1(3.6) ; 19.3$ & $31.9(1.8) ; 22.5$ \\
\hline Place of residence; \%; City & 58.7 & 51.9 & 67.5 \\
\hline Town & 21.7 & 26.9 & 15.0 \\
\hline Rural & 19.6 & 21.2 & 17.5 \\
\hline Vitamin $\mathrm{D}_{3^{\prime}} \mathrm{ng} / \mathrm{ml} ;$ mean $\pm(\mathrm{SD})$ & $21.9(13.0)$ & $20.2(13.2)$ & $24.2(12.6)$ \\
\hline Estradiol, pg/ml, mean $\pm(S D)$ & $20.9(21.0)$ & $5.6(2.3)$ & $40.8(17.3)$ \\
\hline $\mathrm{Ctx}, \mu \mathrm{g} / \mathrm{L} ;$ mean $\pm(\mathrm{SD})$ & $0.54(0.16)$ & $0.55(0.2)$ & $0.54(0.15)$ \\
\hline Osteocalcin, $\mu \mathrm{g} / \mathrm{L} ;$ mean $\pm(\mathrm{SD})$ & $10.7(3.7)$ & $10.1(3.5)$ & $11.5(3.8)$ \\
\hline IL-6, pg/ml; mean $\pm(\mathrm{SD})$ & $2.05(1.87)$ & $1.97(1.9)$ & $2.18(1.8)$ \\
\hline TNF-a, pg/ml; mean $\pm(S D)$ & $3.13(1.69)$ & $3.22(1.76)$ & $3.01(1.60)$ \\
\hline \multicolumn{4}{|l|}{ Lipids; mg/ml; mean \pm (SD) } \\
\hline Total cholesterol & $224.7(44.8)$ & $225.5(47.7)$ & $223.7(41.2)$ \\
\hline HDL-cholesterol & $53.7(13.0)$ & $54.7(13.1)$ & $52.6(13.0)$ \\
\hline Triglycerides & $148.2(61.4)$ & $148.5(63.2)$ & $147.9(59.6)$ \\
\hline LDL-cholesterol & $141.4(44.7)$ & $141.4(48.3)$ & $141.5(40.0)$ \\
\hline
\end{tabular}

IL- 6 and TNF- $\alpha$, and lipids levels were observed between the examined groups according to estradiol level.

Subsequently, the effect of estradiol was investigated on the basic biochemical markers of bone metabolism: OC bone formation marker, and Ctx - bone resorption marker. A positive correlation was found between estradiol and the main bone formation marker - OC, both in all women $(\mathrm{p}=0.041, \mathrm{r}=0.213$ (Fig. 1A) and in the group of women with a decreased level of this hormone $(p=0.020, r=-0.226$ (Fig. 1B). In turn, in the examined women, no correlation was noted between Ctx and the level of estradiol ( $\mathrm{p}=0.559, \mathrm{r}=-0.062)$.

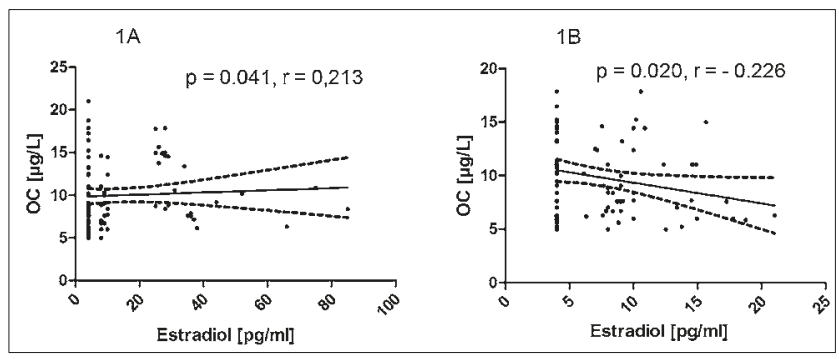

Figure 1. Correlation between osteocalcin $(\mathrm{OC})$ and estradiol in the examined groups of women: 1A Total; 1B Women with a low level of estradiol (Gr-1 $\leq 10 \mathrm{pg} / \mathrm{ml}$ )

In the subsequent part of the analysis, mutual correlations were assessed between biochemical markers of bone metabolism. A significant positive correlation was found between Ctx and OC levels ( $p=0.013 ; r=0.257$ (Fig. 2A). However, no such relationship was discovered in women with a low level of estradiol ( $\mathrm{p}=0.141 ; \mathrm{r}=0.207$ (Fig. 2B).

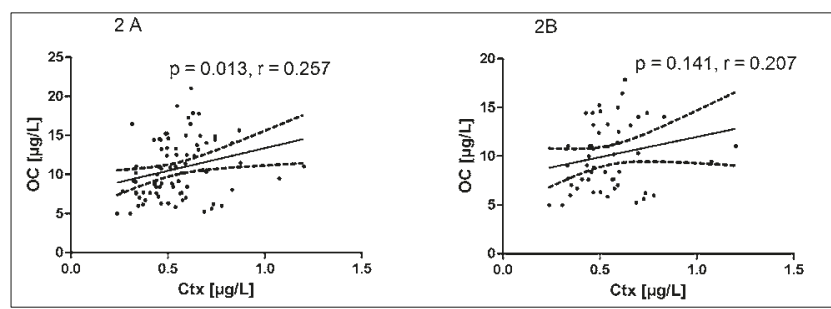

Figure 2. Correlation between C-terminal cross-linked telopeptide of the type I collagen alpha chain (Ctx) and osteocalcin $(\mathrm{OC})$ in the examined groups of women: 1A Total; 1 B Women with a low level of estradiol (Gr-1 $\leq 10 \mathrm{pg} / \mathrm{ml})$

Estrogens may exert an indirect effect on the bone tissue through local secretion of pro-resorptive cytokines: IL-6 and TNF- $\alpha$, as well as vitamin $\mathrm{D}_{3}$. In order to verify this hypothesis, the mutual effect of these factors was evaluated in the examined women. Positive correlations were confirmed between estradiol and the levels of TNF- $\alpha$ and IL- $6(p=0.007$, $r=0.281$ (Fig. 3A) and $p=0.018, r=0.246$ (Fig. 3B), respectively).
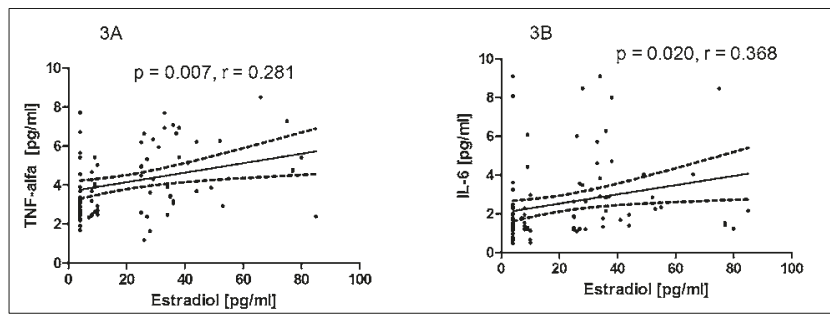

Figure 3. Correlation between estradiol and pro-resorptive cytokines in the examined group of women (Total): $1 \mathrm{~A}$ - tumour necrosis factor-alpha (TNF-a); $1 \mathrm{~B}$ - interleukin 6 (IL-6)

However, in women with a low estradiol level, no such relationship was found. Also, no relationship was observed between the level of estradiol in the examined groups and the level of vitamin $\mathrm{D}_{3}$ (results not shown).

Subsequently, the relationships were investigated between markers of bone remodelling (Ctx and OC), and the level of proresorptive cytokines TNF- $\alpha$ and IL- 6 and vitamin $\mathrm{D}_{3}$, according to estradiol level. The analyses performed did not confirm any relationship between the examined parameters. (Tab. 2 and 3).

Table 2. Correlation between C-terminal cross-linked telopeptide of the type I collagen alpha chain (Ctx) and osteocalcin (OC), and the levels of pro-resorptive cytokines: tumour necrosis factor-alpha (TNF-a) and interleukin 6 (IL-6)

\begin{tabular}{|c|c|c|c|c|c|c|}
\hline & \multicolumn{2}{|c|}{$\begin{array}{c}\text { Postmenopausal } \\
\text { women } \\
n=92\end{array}$} & \multicolumn{2}{|c|}{$\begin{array}{c}\text { Group } 1 \\
n=52\end{array}$} & \multicolumn{2}{|c|}{$\begin{array}{c}\text { Group } 2 \\
n=40\end{array}$} \\
\hline & TNF-a & IL-6 & TNF-a & IL-6 & TNF-a & IL-6 \\
\hline \multirow{2}{*}{ Ctx } & $p=0.042$ & $p=0.701$ & $p=0.573$ & $p=0.674$ & $p=0.578$ & $p=0.119$ \\
\hline & $r=-0.212$ & $r=-0.041$ & $r=0.078$ & $r=0.060$ & $r=0.078$ & $r=-0.250$ \\
\hline \multirow{2}{*}{ Osteocalcin } & $p=0.283$ & $p=0.032$ & $p=0.141$ & $p=0.291$ & $p=0.333$ & $p=0.929$ \\
\hline & $r=0.118$ & $r=0.223$ & $r=0.207$ & $r=0.149$ & $r=-0.157$ & $r=-0.015$ \\
\hline
\end{tabular}

Table 3. Correlation between C-terminal cross-linked telopeptide of the type I collagen alpha chain (Ctx) and osteocalcin (OC), and levels of vitamin D3

\begin{tabular}{ccccccc}
\hline & $\begin{array}{c}\text { Postmenopausal } \\
\text { women } \\
n=92\end{array}$ & \multicolumn{2}{c}{$\begin{array}{c}\text { Group 1 } \\
\mathrm{n}=52\end{array}$} & \multicolumn{2}{c}{$\begin{array}{c}\text { Group 2 } \\
\mathrm{n}=40\end{array}$} \\
\hline $\mathrm{Ctx}$ & $\mathrm{OC}$ & $\mathrm{Ctx}$ & $\mathrm{OC}$ & $\mathrm{Ctx}$ & $\mathrm{OC}$ \\
\hline Vitamin $\mathrm{D}_{3}$ & $\mathrm{P}=0.272$ & $\mathrm{P}=0.444$ & $\mathrm{p}=0.261$ & $\mathrm{p}=0.101$ & $\mathrm{p}=0.844$ & $\mathrm{p}=0.815$ \\
& $\mathrm{r}=-0.115$ & $\mathrm{r}=-0.080$ & $\mathrm{r}=-0.158$ & $\mathrm{r}=-0.230$ & $\mathrm{r}=-0.032$ & $\mathrm{r}=0.038$ \\
\hline
\end{tabular}




\section{DISCUSSION}

The main cause of osteoporosis occurring after menopause is estrogen deficiency, mainly of 17 beta-estradiol by loss of hormonal function of the ovaries. In postmenopausal women the measured levels of estradiol may considerably differ; for example, in a study conducted by Baczyk [13] the level of estradiol was from an undetectable level up to approx. $55 \mathrm{pg} / \mathrm{ml}$.

Estrogen deficiency occurring in women during this period of life may lead to disturbances in the balance of bone metabolism, and reduction in bone mass and bone density which may result in osteoporosis $[6,14]$. Biochemical bone turnover markers (BTM), i.e. bone formation marker (osteocalcin) and bone resorption marker (Ctx), which allow assessment of the current state of bone metabolism, may be used in the evaluation of the risk of fractures. Therefore, an early measurement of BTMs in postmenopausal women may be useful in identification of the risk of osteoporosis and application of hormone replacement therapy [9].

In the current study of postmenopausal women, it was found that the basic bone formation marker - osteocalcin, was weakly positively related to the level of estradiol. Nevertheless, in the group of women with low estradiol level $(5.6 \pm 2.3 \mathrm{pg} / \mathrm{ml})$ this relationship was not observed. Also, no relationship was noted between bone resorption marker Ctx and the level of estradiol. In addition, the determined levels of OC and Ctx in the groups of women with low and normal estradiol levels did not show any differences. These results are in accordance with the studies by other researchers. In a cross-sectional study including 92 healthy women after menopause (mean age 56.2 and 7.2 years after menopause) no relationship was found between the serum levels of OC and Ctx, and the levels of estradiol [15]. Also, other reports concerning postmenopausal women confirmed the lack of relationship between markers of bone turnover and levels of estradiol. However, while interpreting these results it should be kept in mind that, e.g. the level of Ctx is characterized by a significant circadian rhythm, and many diseases and methods of treatment affect BTM $[16,17]$.

The study confirmed a positive correlation between the levels of two main markers of bone turnover: Ctx and osteocalcin (OC), which may evidence that in the examined women after menopause, the processes of bone formation and resorption were balanced. However, this process was not observed in women with a low estradiol level. Similar results were obtained by Li et al. [18] in a study conducted among healthy Chinese postmenopausal women. In other studies [19], a positive correlation between Ctx and OC was also observed in all examined groups of postmenopausal women, also in a group of women with osteoporosis which was probably characterized by low estradiol level.

Some studies indicate the effect of estradiol on the production of pro-inflammatory cytokines in postmenopausal women [20]. Estrogens attenuate the production of cytokine TNF- $\alpha$, and its deficiency associated with the menopausal period may stimulate pro-resorptive cytokines, such as TNF- $\alpha$ and IL-6. These results have been confirmed in studies which indicated a decrease in TNF- $\alpha$, together with an increase in the level of estrogens and a negative correlation between IL- 6 a estradiol in the serum of postmenopausal women [20,21]. In the current study, both lower levels of TNF- $\alpha$ and a negative correlation between estradiol and pro-resorptive cytokines were observed in the group of women with low levels of estradiol; however, they were statistically insignificant.

Pro-resorptive cytokines TNF- $\alpha$ and IL- 6 may exert an effect on the differentiation, proliferation, and apoptosis of osteoblasts and osteoclasts, through autocrine and paracrine action, in this way regulating bone metabolism [14]. Therefore, in the presented study, the relationship was investigated between the main markers of bone resorption Ctx and OC formation, and the pro-resorptive markers TNF- $\alpha$ and IL6 . The analysis performed confirmed a negative correlation between Ctx and TNF- $\alpha$, and a positive correlation between OC and IL-6. No effect of estradiol on these relationships was noted. Different results were presented by Chen YN et al. [22], who indicated that the serum level of Ctx was positively related with both TNF- $\alpha$ and IL- 6 . In addition, they confirmed an increase in the levels of bone turnover markers Ctx and OC, and pro-inflammatory cytokines TNF- $\alpha$ and IL- 6 in the examined postmenopausal women. These differences may result from the characteristics of the examined women which differed from those in the presented study. In a study by Chen YN et al., in which participated women diagnosed with osteoporosis and additional, accompanying diseases, including pro-inflammatory cardiovascular diseases [22].

Deficiency of vitamin D3 is a common phenomenon concerning the whole population. The main causes are primarily an inadequately balanced diet, differences in exposure to sunlight, age, gender, body weight, ethnic origin, genetic predisposition [23], as well as the concentration of DBP - Vitamin D-binding Protein [24]. The concentration of DBP depends on the level of estradio, as demonstrated in the study by Pop LC et al. [24], in which the authors showed a correlation between the level of estradiol and DBP, as well as the level of total $25(\mathrm{OH}) \mathrm{D} 3$ vitamin.

In women after menopause due to the cessation of hormonal ovarian function, and consequently, a decrease in the level of estrogens, a decrease occurs in the concentration of vitamin D3, which is responsible for the maintenance of calcium homeostasis. Its very low levels are associated with the occurrence of osteomalacia, while high levels may increase bone resorption and deteriorate mineralization; it is therefore very important to maintain it on a proper level [23].

Vitamin D3, opposite to osteocalcin, is less bone-specific. It has no basic effect on bone tissue and acts more like a hormone, and the results of some studies show that it may act on bones through osteocalcin [25]. These observations were confirmed in a study which included a group of 200 postmenopausal women, where a significant positive correlation was found between the level of vitamin D3 and osteocalcin [26]. Nevertheless, other studies did not confirm a significant effect of therapy with vitamin $\mathrm{D}$ on bone turnover evaluated using the markers Ctx and OC [27]. In the presented study, a positive correlation was confirmed between the level of vitamin D3 and estradiol in the total group of the examined women, including the group with a low level of estradiol. In turn, no correlation was observed between the level of vitamin D3 and bone turnover markers - Ctx and osteocalcin. Similarly, vitamin D supplementation had no additional effect on bone turnover markers in patients with serum concentration of $25(\mathrm{OH}) \mathrm{D}$ below $30 \mathrm{ng} / \mathrm{ml}$ [27].

However, the current study has some limitations. Earlier, the associations between dietary patterns, bone turnover and bone mineral density (BMD) were shown. Unfortunately, in this study the participants were not examined to assess 
bone mineral density. Bone density scanning, also called DXA (dual-energy $x$-ray absorptiometry), is effective in tracking the effects of treatment for osteoporosis and other conditions that cause bone loss. The DXA scan analysis is commonly used to diagnose osteoporosis and to assess an individual's risk for developing osteoporotic fractures. Also, the nutritional pattern of the postmenopausal women was not studied, although it is known that eating habits may influence both bone turnover and BMD.

\section{CONCLUSIONS}

Summing-up, the postmenopausal women in the study who hada low level of estradiol were characterized by impaired bone turnover. A relationship was found between the level of estrogen and the concentration of pro-resorptive cytokines TNF- $\alpha$ and IL- 6 , and a relationship between TNF- $\alpha$ and bone resprption marker Ctx, and IL- 6 and bone formation marker OC. Positive correlations were also observed between estradiol and vitamin $\mathrm{D}_{3}$, also in women with a low hormone level; however, no relationship was found between vitamin $\mathrm{D}_{3}$ and bone turnover markers Ctx and osteocalcin. Finally, no relationship was confirmed between body mass index (BMI) and the examined parameters of bone turnover.

\section{REFERENCES}

1. Rizzoli R. Postmenopausal osteoporosis: Assessment and management. Best Pract Res Clin Endocrinol Metab. 2018; 32(5): 739-57. doi.10.1016/j. beem

2. Janiszewska M, Barańska A, Jędrych T, Kulik T, Kasperek J, Drop B. The impact of selected factors on acceptance of illness and life satisfaction among female residents of rural areas treated for osteoporosis. Ann Agric Environ Med. 2019; 26(4): 592-599. doi.10.26444/aaem/109598

3. Almeida M, Laurent MR, Dubois V, et al. Estrogens and Androgens in Skeletal Physiology and Pathophysiology. Physiol Rev. 2017; 97: 135-187. doi: 10.1152/physrev.00033.2015

4. Katsimbri, P. The biology of normal bone remodelling. Eur J Cancer Care (Engl). 2017; 26(6): e12740. doi.10.1111/ecc.127402017

5. Møller AMJ, Delaissé JM, Olesen JB, et al. Aging and menopause reprogram osteoclast precursors for aggressive bone resorption. Bone Res. 2020; 8: 27. doi. 10.1038/s41413-020-0102-7

6. Levin VA, Jiang X, Kagan R. Estrogen therapy for osteoporosis in the modern era. Osteoporos Int. 2018; 29(5): 1049-1055. doi: 10.1007/ s00198-018-4414-z

7. Khalid AB, Krum SA Estrogen receptors alpha and beta in bone. Bone. 2016; 87: 130-135. doi.10.1016/j.bone.2016.03.016

8. Almeida M, Laurent MR, Dubois V, et al. Estrogens and Androgens in Skeletal Physiology and Pathophysiology. Physiol Rev. 2017; 97: 135-187. doi: 10.1152/physrev.00033.2015

9. Eastell R, Szulc P. Use of bone turnover markers in postmenopausal osteoporosis. Lancet Diabetes Endocrinol. 2017; 5: 908-23. doi: 10.1016/ S2213-8587(17)30184-5

10. Szulc P, et al. Use of CTX-I and PINP as bone turnover markers: National Bone Health Alliance recommendations to standardize sample handling and patient preparation to reduce pre-analytical variability. Osteoporos Int. 2017; 28: 2541-56. doi: 10.1007/s00198-017-4082-4
11. Wheater G, Elshahaly M, Tuck SP, et al. The clinical utility of bone marker measurements in osteoporosis. J Transl Med. 2013 Aug; 11: 201. doi. 10.1186/1479-5876-11-201

12. Bojar I, Lyubinets O, Novotny J, et al. Intensification of menopausal symptoms among female inhabitants of East European countries. Ann Agric Environ Med. 2016; 23(3): 517-524. doi.10.5604/12321966.1219198

13. Baczyk G, Chuchracki M, Klejewski A. The relationship between selected biochemical parameters, clinical factors and bone mineral density in postmenopausal women with osteoporosis. Ginekol Pol. 2012 Mar; 83 (3): 194-201.

14. Park SG, Jeong SU, Lee JH, et al. The Changes of CTX, DPD, Osteocalcin, and Bone Mineral Density During the Postmenopausal Period. Ann Rehabil Med. 2018 Jun; 42(3): 441-448. https://doi.org/10.5535/ arm.2018.42.3.441

15. García-Martín A, Reyes-García R, García-Castro JM, et al. Role of serum FSH measurement on bone resorption in postmenopausal women. Endocrine. 2012 Apr; 41 (2): 302-308. https://doi.org/10.1007/ s12020-011-9541-7

16. Pardhe BD, Pathak S, Bhetwal A, et al. Effect of age and estrogen on biochemical markers of bone turnover in postmenopausal women: a population-based study from Nepal. Int J Womens Health. 2017; 9: 781-788. doi.org/10.2147/IJWH.S145191

17. Gossiel F, Finigan J, Jacques R, et al. Establishing reference intervals for bone turnover markers in healthy postmenopausal women in a nonfasting state. Bonekey Rep. 2014; 3: 573. doi.org/10.1038/ bonekey.2014.68

18. Li C, Chen P, Duan X, et al. Bioavailable 25(OH)D but Not Total $25(\mathrm{OH}) \mathrm{D}$ Is an Independent Determinant for Bone Mineral Density in Chinese Postmenopausal Women. EBioMedicine. 2017; 15: 184-192. doi.org/10.1016/j.ebiom.2016.11.029

19. Naeem ST, Hussain R, Raheem A, et al. Bone Turnover Markers for Osteoporosis Status Assessment at Baseline in Postmenopausal Pakistani Females. J Coll Physicians Surg Pak. 2016 May; 26(5): 408412.

20. Liu Y-P, Li J, Xin S-B. Study the relevance between inflammatory factors and estradiol and their association with knee osteoarthritis in postmenopausal women. Eur Rev Med Pharmacol Sci. 2018; 22(2): 472-478. doi: 10.26355/eurrev_201801_14197

21. Malutan AM, Dan M, Nicolae C, Carmen M. Proinflammatory and anti-inflammatory cytokine changes related to menopause. Prz Menopauzalny. 2014; 13(3): 162-8. doi: 10.5114/pm.2014.43818

22. Chen YN, Wei P, Yu Bs J. Higher concentration of serum C-terminal cross-linking telopeptide of type I collagen is positively related with inflammatory factors in postmenopausal women with H-type hypertension and osteoporosis. Orthop Surg. 2019; 11(6): 1135-1141. https://doi.org/10.1111/os.12567

23. Kocka KH, Ślusarska BJ, Nowicki GJ, et al. Level of vitamin $25(\mathrm{OH}) \mathrm{D}$ and $\mathrm{B}$ group vitamins and functional efficiency among the chronically ill elderly in domiciliary care - a pilot study. Ann Agric Environ Med. 2019; 26(3): 489-495. doi: 10.26444/aaem/105801

24. Pop LC, Shapses SA, Chang B, et al. Vitamin D-binding protein in healthy pre- and postmenopausal women: relationship with estradiol concentrations. Endocr Pract. 2015 Aug; 21 (8): 936-942. https://doi. org/10.4158/EP15623.OR

25. Guney G, Sener-Simsek B, Tokmak A, et al. Assessment of the Relationship between Serum Vitamin D and Osteocalcin Levels with Metabolic Syndrome in Non-Osteoporotic Postmenopausal Women. Geburtshilfe Frauenheilkd. 2019 Mar; 79(03): 293-299. https://doi. org/10.1055/a-0767-6572

26. Al-Daghri NM, Yakout S, Al-Shehri E, et al. Inflammatory and bone turnover markers in relation to PTH and vitamin D status among Saudi postmenopausal women with and without osteoporosis. Int J Clin Exp Med. 2014 Sep 15; 7(9): 2812-2819.

27. Schwetz V, Trummer C, Pandis M, et al. Effects of Vitamin D Supplementation on Bone Turnover Markers: A Randomized Controlled Trial. Nutrients. 2017; 9(5): 432. https://doi.org/10.3390/nu9050432 